\title{
O DIREITO À CIDADE E A PARTICIPAÇÃO POPULAR NO PLANEJAMENTO URBANO MUNICIPAL
}

\section{THE RIGHT TO THE CITY AND POPULAR PARTICIPATION IN DISTRICT URBAN PLANNING}

\author{
Émilien Vilas Boas Reis ${ }^{1}$ \\ Stephanie Rodrigues Venâncio²
}

\begin{abstract}
Resumo
O presente trabalho, por meio de análise doutrinária, objetiva demonstrar a importância do planejamento da atuação do Poder Público, de forma a direcionar as políticas urbanas na garantia do bem-estar dos indivíduos, em atenção ao princípio da função social da cidade. Destaca-se, para tanto, a importância do Plano Diretor, previsto na Constituição Federal de 1988 e na Lei 10.257, de 2001, denominada Estatuto da Cidade, enquanto principal instrumento de desenvolvimento e expansão urbana, orientando o exercício da Administração Pública municipal em atenção ao desenvolvimento sustentável das cidades. Pretende-se, ainda, atestar a essencialidade da gestão compartilhada da cidade, demonstrando-se, dessa forma, a potencialidade das audiências públicas na gestão eficiente dos espaços urbanos, propiciando a transparência das decisões políticas, com fins de justiça social, ressaltando-se, ainda, a essencialidade de uma participação popular eficaz na elaboração e atualização do Plano Diretor, conduzindo a uma gestão democrática e eficiente da cidade, legitimando a atuação do poder público, que deve estar intimamente vinculada aos anseios sociais. O presente trabalho busca, dessa forma, analisar, através do método indutivo-dedutivo, a gestão participativa do meio ambiente urbano, na construção de uma sociedade integradora, gestão está direcionada na implantação de políticas públicas eficazes na garantia do bem-estar de todos.
\end{abstract}

Palavras-chave: Cidade; Sustentabilidade; Planejamento; Gestão; Participação popular.

\section{Abstract}

The present work, by doctrinaire, objective analysis shows the importance of the Government action planning in order to direct the urban policies in ensuring the welfare of individuals in regard to the principle of the social function of the city. It is noteworthy, therefore, the importance of the Plan provided for in the Federal Constitution of 1988 and Law 10.257 of 2001, known as the City Statute, as the main tool for development and urban expansion, guiding the exercise of municipal Public Administration attention sustainable development of cities. It is intended also attest to the essentiality of the shared management of the city, demonstrating thus the potential of public hearings in the efficient management of urban spaces, providing transparency of political decisions, social justice purposes, emphasizing Furthermore, the essentiality of an effective popular participation in the development and updating of the Master Plan, leading to a democratic and efficient management of the city, legitimizing the government's actions, which should be closely linked to social expectations. This study aims, therefore, to analyze, through the inductive-

\footnotetext{
1 Pós-doutor em Filosofia pela Faculdade de Letras da Universidade do Porto (Portugal). Professor de Filosofia e Filosofia do Direito da Graduação e do Mestrado em Direito Ambiental e Desenvolvimento Sustentável da Escola Superior Dom Helder Câmara (Belo Horizonte - MG). E-mail: mboasr@yahoo.com.br

2 Graduada em Direito pela Pontifícia Universidade Católica de Minas Gerais. E-mail: ste_rodrigues06@yahoo.com.br
} 
deductive method, participatory management of the urban environment, building an inclusive society, managing this targeted in the implementation of effective public policies in ensuring the welfare of all.

Keywords: City; Sustainability; Planning; Management; Popular Participation. 


\section{INTRODUÇÃO}

O artigo 225, da Constituição Federal, ao assegurar que todos têm direito ao meio ambiente ecologicamente equilibrado, impôs ao Poder Público e à coletividade o dever de defendê-lo e preservá-lo, de modo a garantir a sadia qualidade de vida para as presentes e futuras gerações. (BRASIL, 1988). Para que o Poder Público realize suas funções, ele deve planejar suas ações, de modo a garantir uma gestão adequada do meio social. Esse planejamento, por óbvio, deve ser participativo, de modo que as políticas urbanas estejam sempre direcionadas aos anseios sociais.

O meio ambiente urbano, materializado pela cidade, demanda um arcabouço normativo especial, com vistas a assegurar uma existência com dignidade a todos os indivíduos. Dessa forma, objetivando regular os arts. 182 e 183, do texto constitucional, que dispõem sobre a política de desenvolvimento urbano, a Lei 10.257, promulgada em 2001, estabeleceu diversas diretrizes a serem atendidas para uma adequada e eficiente gestão do espaço urbano.

O Estatuto da Cidade visa assegurar um planejamento apropriado das políticas urbanas, como forma de garantir a observância dessa gestão eficiente da cidade, dispondo sobre diversos instrumentos hábeis à concretizar o desenvolvimento sustentável do meio ambiente urbano. $\mathrm{O}$ Plano Diretor, previsto na Lei 10.257/2001 como principal instrumento da política de desenvolvimento e expansão urbana, apresenta-se como mecanismo apto a garantir o planejamento da atuação do Poder Público, possibilitando a gestão ordenada das cidades, aliando a atuação do Poder Público e a participação da sociedade civil, no direcionamento das ações estatais, na consecução do bem-estar dos indivíduos.

O presente artigo pretende, dessa forma, demonstrar a importância do planejamento urbano municipal, direcionando as políticas urbanas na garantia do bem-estar dos indivíduos, destacando-se a importância do plano diretor enquanto principal instrumento do planejamento da atuação estatal, voltado ao desenvolvimento sustentável das cidades. Objetiva-se demonstrar a essencialidade da participação popular no estado democrático de direito, na construção de uma sociedade integradora e justa. Analisa-se, ainda, a potencialidade das audiências públicas na gestão eficiente dos espaços urbanos, propiciando a transparência das decisões políticas, com fins de justiça social, ressaltando-se a essencialidade de uma participação popular eficaz na elaboração e atualização do plano diretor. 
Através do método indutivo-dedutivo, objetiva-se demonstrar a imprescindibilidade da participação popular nas deliberações urbanísticas realizadas pela Administração Pública, destacando-se a substancialidade da gestão compartilhada da cidade, direcionando a atuação da Administração Pública no atendimento das necessidades sociais de cada um dos indivíduos, que passam a ser reconhecer mutuamente enquanto agentes transformadores do meio em que vivem. Com o levantamento das principais posições doutrinárias a respeito do tema, destacou-se a importância da participação da sociedade civil no planejamento das políticas urbanas, com vistas ao desenvolvimento sustentável das cidades, construindo-se, assim, uma sociedade integradora.

\section{O DIREITO À CIDADE E A TRANSFORMAÇÃO DA REALIDADE URBANA ATRAVÉS DO PLANEJAMENTO}

O meio ambiente urbano, entendido como o meio alterado pelo homem, é representado pela cidade (MARQUES, 2010), enquanto espaço de convivência dos indivíduos, dotada de toda uma infraestrutura composta por bens e serviços públicos, que têm por objetivo o bem-estar de seus habitantes. De acordo com Celso Antônio Pacheco Fiorillo (2013, p. 79), o meio ambiente artificial "está diretamente relacionado ao conceito de cidade", entendido, portanto, como espaço urbano de convivência social, materializador das atividades humanas e garantidor de direitos fundamentais. É nesse sentido que a cidade é compreendida como o habitat natural do homem, onde os indivíduos exercitam suas capacidades.

Em razão de sua essencialidade à existência digna de todos os indivíduos, a cidade demanda um arcabouço normativo especial, motivo pelo qual o Estatuto da Cidade (Lei 10.257/2001) foi editado com o objetivo maior de garantir o pleno desenvolvimento sustentável do meio urbano, dispondo em seu artigo $2^{\circ}$, I:

Art. 2 A política urbana tem por objetivo ordenar o pleno desenvolvimento das funções sociais da cidade e da propriedade urbana, mediante as seguintes diretrizes gerais:

I. Garantia do direito a cidades sustentáveis, entendido como o direito à terra urbana, à moradia, ao saneamento ambiental, à infraestrutura urbana, ao transporte e aos serviços públicos, ao trabalho e ao lazer, para as presentes e futuras gerações. (BRASIL, 2001).

A cidade revela-se como o centro da vida humana, que demanda atenção especial do Estado no que diz respeito ao desenvolvimento das capacidades de cada um dos indivíduos, revelando-se como meio necessário a garantir os direitos básicos do povo, entendido, assim, como o próprio direito à cidade. 
É no meio urbano que também se verifica a importância da função social da propriedade direcionada ao bem-estar de todos, à medida que o próprio Estatuto traça as diretrizes na regulamentação do uso da propriedade urbana em benefício dos interesses coletivos, dispondo de instrumentos tributários e jurídicos, como impostos sobre a propriedade e desapropriação, respectivamente, na consecução do desenvolvimento urbano sustentável.

Embora compreendida como núcleo do meio ambiente artificial (COSTA; RIOS, 2013) e indispensável à existência humana com dignidade, verifica-se, na atualidade, cada vez de forma mais aparente, que a cidade, entendida como a necessidade do outro (PLATÃO, 2000), apresentase como um meio de segregação social, gerador de impactos ambientais.

Observa-se, de fato, uma crescente desconsideração das questões socioambientais diante do desenvolvimento urbano, principalmente no que tange às irregularidades do parcelamento e da ocupação do solo, da degradação da natureza, do consumo exacerbado e da ausência de planejamento das próprias políticas públicas, que hoje se voltam, primordialmente, em atenção ao crescimento econômico, com o acirramento da crise ambiental e das desigualdades sociais, implicando, consequentemente, na deterioração da qualidade de vida na cidade. Nesse sentido, evidencia-se que a relação entre meio ambiente e desenvolvimento socioeconômico apresenta-se fraturada, conforme asseverado por Henrique Leff (2011), em decorrência de um avanço econômico e tecnológico desconhecedor dos problemas ambientais e sociais.

Esse desenvolvimento econômico, portanto, pautado na racionalidade científica, implica, consequentemente, na ausência de políticas públicas direcionadas ao atendimento dos anseios sociais, acarretando, assim, a crescente exclusão das minorias e a ausência de planejamento para um desenvolvimento urbano adequado.

Sobre a desconsideração das questões sociais e ambientais, José Roberto Marques (2010, p. 91) sustenta que "a cidade criada para suprir as necessidades do homem e proporciona-lhe bem-estar e segurança acabou revelando-se um importante elemento que contra ele age, deteriorando sua qualidade de vida".

Diante de tal quadro e no que diz respeito ao desenvolvimento das cidades e a necessária proteção do meio ambiente e garantia de direitos sociais, impõe-se uma alteração de postura, tanto dos indivíduos, por meio de uma educação ambiental, quanto da administração pública, mediante políticas públicas efetivas, que garantam o bem-estar de todos.

Mostra-se evidente que as políticas públicas de desenvolvimento urbano devem atentarse a essas implicações, corroborando tal afirmativa a lição de Édis Milaré (2011, p. 345), segundo a 
qual "uma vez aceito o caráter holístico do meio ambiente como produto das interações e relações da sociedade humana com o mundo natural, o meio ambiente construído, ou artificial, passa a ser objeto das políticas ambientais."

Dessa forma, a cidade não mais pode ser concebida como um meio gerador de impactos ambientais e sociais, em razão da supervalorização dos direitos individuais sobre os direitos sociais e do homem em relação à natureza, mas deve ser entendida como meio garantidor do direito à vida digna, emergindo, daí a função social da cidade. (FIORILLO, 2013).

De fato, não há como prosperar as aspirações a um desenvolvimento sustentável do meio ambiente urbano sem antes conferir às cidades uma infraestrutura mínima capaz de garantir aos indivíduos uma vida digna, correspondendo, por óbvio, ao equilíbrio do meio ambiente, vital à vida humana.

Corroborando, ainda, a função social da cidade, enquanto garantia de direitos fundamentais, o legislador, ao regular os arts. 182 e 183, da Constituição Federal, editou a Lei 10.257/2001 (Estatuto da Cidade), conforme destacado anteriormente, objetivando a compatibilização entre desenvolvimento urbano e proteção da natureza.

O Estatuto da Cidade, enquanto instrumento jurídico das políticas públicas direcionadas à persecução do desenvolvimento urbano sustentável, consagra a participação popular e a atuação do poder público, como garantidores da função social da cidade, nos termos destacados por Cláudia do Amaral Furquim:

Essas características da legislação geral urbanística demonstram que o planejamento urbano atua em todas as direções de convivência social. Muito mais do que simplesmente uma acomodação de interesses patrimoniais, é uma tentativa de acomodar a fixação da sociedade sobre um território de maneira responsável, dando a cada um mais do que a oportunidade de explorar a sua riqueza dominial, mas sobretudo a de contribuir para a melhoria da qualidade de vida da cidade. (FURQUIM, 2012, p. 75).

O Estatuto da Cidade, portanto, evidenciou um avanço da legislação brasileira em relação à proteção do meio ambiente ecologicamente equilibrado em detrimento do crescimento desordenado das cidades, considerando que, por muito tempo, a questão ambiental e social foi relegada, diante do inerente desenvolvimento econômico. Partindo de tais premissas, verifica-se que a cidade, espaço de convivência humana, pressupõe ampla compatibilização entre desenvolvimento econômico, proteção dos recursos naturais e garantia de direitos individuais e difusos. É nesse sentido que a transformação da cidade depende, primordialmente, de políticas públicas eficientes, que garantam o bem-estar de todos, conforme destaca Fiorillo: 
A política urbana estabelece como um dos princípios o pleno desenvolvimento das funções sociais da cidade. Aplenitude vislumbrada pela norma encontra-se satisfeita quando do efetivo respeito aos preceitos trazidos pelos arts. 50 e 60 da Constituição Federal. Isso significa dizer que a função social da cidade é cumprida quando esta proporciona a seus habitantes o direito à vida, à segurança, à igualdade, à propriedade e à liberdade (CF, art. 5o, caput), bem como quando garante a todos um piso vital mínimo, compreendido pelos direitos sociais à educação, à saúde, ao lazer, ao trabalho, à previdência social, à maternidade, à infância, à assistência aos desamparados, entre outros encartados no art. 6ㅇ. (FIORILLO, 2013, p. 557).

Cabe ao Poder Público, portanto, através de políticas urbanas devidamente planejadas, viabilizar a observância efetiva da função social da cidade, garantindo aos indivíduos condições de vida com dignidade. Nesse contexto, torna-se essencial a compreensão do processo de urbanização ocorrido no Brasil, primordialmente a partir da década de 1930 (MURAD, 2010), que transformou por completo o quadro socioambiental do país.

\section{O processo de urbanização no Brasil e a essencialidade do planejamento das políticas urbanas}

O aumento do contingente populacional nas áreas urbanas operou uma transformação das cidades, transformando-as em espaços complexos de inter-relações pessoais e de intervenção do homem na natureza. A urbanização, caracterizada como o aumento da concentração da população na área urbana, em detrimento da área rural, mostra-se, no Brasil, como um processo desvinculado do essencial desenvolvimento da infraestrutura urbana, demonstrando uma completa disparidade entre expansão urbana e garantia de direitos fundamentais, gerando "processos renovados de exclusão social, crise habitacional, segregação espacial, violência urbana e degradação ambiental." (FERNANDES, 2006, p. 3).

O crescimento desordenado das cidades brasileiras, causado, em parte, pela omissão do Estado no tocante ao planejamento eficiente das políticas urbanas, resultou, assim, em um adensamento demográfico gerador de impacto ambiental e exclusão social, nos termos preconizados por Edésio Fernandes:

No Brasil, paradigma regional do melhor e do prior do desenvolvimento urbano, mais de $80 \%$ da população vive em cidades. Desde a década de 1930, e mais especialmente desde a década de 1960, a urbanização rápida tem estruturalmente transformado o país em termos territoriais, socioeconômico, culturais e ambientais.De acordo com dados recentes de diversas fontes, 26 milhões de brasileiros que vivem em áreas urbanas não têm água em casa; 14 milhões não são atendidos por coleta de lixo; 83 milhões não estão conectados a sistema de saneamento; e 70\% do esgoto 
coletado não é tratado, mas jogado em estado bruto da natureza. (FERNANDES, 2006, p. 4).

O meio ambiente urbano, entendido como o habitat natural do homem, passa a ser concebido, dessa forma, como um espaço violador de direitos humanos, em razão da flagrante ineficiência da atuação estatal na implantação de políticas públicas primordiais ao desenvolvimento adequado da cidade. De fato, o aumento do contingente populacional não vem acompanhado do aperfeiçoamento da infraestrutura urbana, que se mostra incapaz, portanto, de garantir aos indivíduos condições de vida digna na cidade.

Diante do adensamento demográfico urbano desordenado e em razão da omissão estatal frente aos anseios da sociedade por uma infraestrutura urbana de qualidade, a cidade passa a se desenvolver de acordo com o mercado imobiliário e a população mais carente, que passa a ser concebida como uma mera consequência do processo de urbanização e do essencial desenvolvimento econômico, sendo direcionada, portanto, para áreas mais afastadas, menos urbanizadas e sem qualquer infraestrutura urbana adequada.

Renato Cymbalista, ao destacar as implicações decorrentes da omissão estatal no tocante ao processo de urbanização no Brasil, assevera que:

a urbanização vertiginosa, ao final de um período de acelerada expansão da economiabrasileira, introduziu um novo e dramático significado: as cidades, nesse período, passaram aretratar - e reproduzir - as injustiças e desigualdades da sociedade. (CYMBALISTA, 2005, p. 6).

É nesse quadro de desenvolvimento e expansão urbana, sem qualquer forma de planejamento racional, que a cidade cresce desordenadamente, de modo que os indivíduos passam a ser privados dos direitos fundamentais mínimos, como à moradia digna, à educação, ao lazer, à saúde, entre outros.

José Afonso da Silva leciona que a urbanização ocasiona enormes implicações no meio ambiente, eis que "deteriora o ambiente urbano. Provoca a desorganização social, com carência de habitação, desemprego, problemas de higiene e de saneamento básico. Modifica a utilização do solo e transforma a paisagem urbana." (SILVA, 2010, p. 26). A solução para esses problemas, segundo o autor, seria, então, a intervenção do Poder Público, que procura transformar o meio urbano e criar novas formas urbanas, de modo a promover verdadeira transformação da realidade urbana desordenada.

A atuação estatal planejada mostra-se, dessa forma, essencial na correção dessas falhas ocasionadas pelo processo de urbanização, atuação essa denominada de urbanificação, entendida 
como "a operação posterior ao ato de urbanizar, quando nesse último caso forem detectadas correções a serem feitas: urbanificar é corrigir falhas da urbanização". (ALOCHIO, 2010, p. 67).

A urbanificação, enquanto processo de transformação da realidade urbana insatisfatória (ALOCHIO, 2010) somente será possível através do planejamento das ações do Estado, de forma que as políticas urbanas sejam condizentes com a realidade da cidade, atentando-se para suas peculiaridades socioambientais e estruturais, conforme assevera Elizandra Litaiff Leonardo:

Uma obrigação fundamental do Estado, no que concerne aos espaços humanos habitados, é adotar o planejamento como uma sistemática para avaliação de necessidades, problemas e oportunidades e, assim, ter capacidade de conduzir o crescimento e desenvolvimento urbanos pautado na sustentabilidade dos recursos disponíveis. (LEORNARDO, 2010, p. 6782).

Ainda sobre a essencialidade do planejamento das políticas urbanas, Edésio Fernandes leciona:

Não se pode esquecer que, no acesso à terra estão implicados direitos humanos tipicamente prestacionais, não sendo razoável julgar-se o Estado isento da responsabilidade, enquanto o tal acesso fique permanente suspenso à espera de que, finalmente, os chamados limites do possível, com que ele costuma se desculpar, sejam alcançados. (...) Não é por acaso que muitos governos, a si mesmos e ao povo apresentados como democráticos, mas infiéis às promessas constitucionais de justiça social às quais juraram cumprir, geram tanta insatisfação popular por passarem o tempo todo de sua gestão, confundindo "governabilidade" com uma submissão servil a um modelo de distribuição dos bens e da terra, totalmente indiferente à tal justiça. (FERNANDES, 2006, p. 173).

É, portanto, através do planejamento das políticas públicas, que o Estado passa a atuar de

forma eficiente na transformação dessa realidade urbana violadora de direitos fundamentais, decorrente do irracional processo de urbanização do país.

O planejamento, nesse contexto, é compreendido como instrumento direcionador das ações estatais na correção das falhas decorrentes do processo de urbanização desordenada, bem como na concretização dos direitos sociais, conduzindo a cidade a níveis de desenvolvimento sustentável, de modo que ela passa a ser pensada de forma otimizada, direcionada ao fim precípuo do Estado: o bem-estar dos seus habitantes, confirmando a lição de José Roberto Marques, segundo a qual "cidades planejadas significam melhor qualidade de vida para as gerações futuras". (MARQUES, 2010, p. 188).

Partindo-se para uma visão crítica do planejamento urbano realizado no Brasil, Luiz Henrique Antunes Alochio destaca:

Não se pode continuar acreditando cegamente na ilusão de que o planejamento pelo planejamento seja a solução. É preciso reconhecer, como adverte Hall, que o planejamento muitas vezes pode degenerar "numa 
máquina reguladora negativa, projetada para sufocar toda e qualquer iniciativa, toda e qualquer capacidade criadora". Eckardt afirma que, invariavelmente, os planejadores esquecem que o sucesso de um planejamento não depende apenas do que é feito, mas de como é feito, no que deveria perder força a idéia ainda reinante de projetos predeterminados. (ALOCHIO, 2010, p. 87).

Evidencia-se, de fato, que o planejamento das políticas urbanas sempre deve estar fundado em uma perspectiva dinâmica, de modo que também possa ser eficiente em relação aos anseios sociais que se modificam e evoluem em um curto espaço de tempo. A esse respeito, Luiz Henrique Antunes Alochio também assevera que o planejamento da atuação estatal deve orientarse para o futuro, de modo a corresponder ao dinamismo social, levando em consideração "as temporalidades dos elementos economicamente hegemônicos da cidade". (ALOCHIO, 2010, p. 87).

O planejamento urbanístico emerge como instrumento essencial na transformação de uma realidade urbana insatisfatória, sendo certo que os planos municipais mostram-se imprescindíveis na gestão eficiente das cidades, até mesmo pela própria proximidade do poder local com as necessidades e anseios sociais, conforme destaca Benedicto de Vasconcellos Luna Gonçalves Patrão e Rosângela Maria de Azevedo Gomes:

Diante do quadro de incertezas acarretadas pelo atual quadro de desordem urbana, é que o papel do Município ganha notória relevância, diante da sua inata destreza na busca pelo desenvolvimento de políticas públicas (...). Nesta sua vocação natural, qualquer projeto, que vise superar o caos urbano, deve ter plena consciência da natureza e dinâmica locais em que se concentram os problemas de uma determinada cidade. (GOMES; PATRÃO, 2014, p. 51-52).

Ressalta-se, portanto, a função do Poder Público de planejamento de suas atividades, na consecução dos anseios sociais e na própria atuação da Administração Pública de forma eficiente e atenta aos anseios sociais, concluindo Mariana Mencio:

que a Constituição Federal e o Estatuto da Cidade expressamente relacionam, no âmbito do Direito Urbanístico, a função política, consistente na atividade de ordenação das cidades, por meio de planos, e a função administrativa, consistente na intervenção da propriedade privada, baseada na execução de Planos Diretores. (MENCIO, 2007, p. 28).

Partindo-se de tais considerações, a planificação municipal, instrumentalizada através do Plano Diretor, expressamente previsto no Estatuto da Cidade, mostra-se primordial no ordenamento das cidades, de modo a direcionar a atuação estatal e as atividades dos munícipes na consecução do desenvolvimento sustentável das cidades, garantindo, por consequência, uma vida digna a todos, a teor do disposto no art. 225, da Constituição Federal. 


\section{O plano diretor na gestão do espaço urbano}

O art. 30, da Constituição Federal, ao estabelecer a competência dos Municípios para legislar sobre assuntos de interesse local, corrobora a importância da atuação do gestor municipal pautada em uma legislação eficiente, que corresponda aos anseios da população local. O próprio texto constitucional, ao dispor sobre a política de desenvolvimento urbano, asseverou, em seu art. $182, \S 1^{\circ}$, que ao Município compete ordenar o pleno desenvolvimento das funções sociais da cidade, utilizando-se, para tanto, do principal instrumento de planejamento da política de desenvolvimento e expansão urbana: o plano diretor, que, na lição de Paulo Affonso Leme Machado:

é um conjunto de normas obrigatórias, elaborado por lei municipal específica, integrando o processo de planejamento municipal, que regula as atividades e os empreendimentos do próprio Poder Público Municipal e das pessoas físicas ou jurídicas, de Direito Privado ou Público, a serem levados a efeito no território municipal. (MACHADO, 2007, p. 389).

O planejamento das ações do ente municipal afigura-se imprescindível na persecução eficiente de sua função, qual seja, o bem-estar dos indivíduos. Tal planejamento deve direcionar a atuação do gestor público de forma mais eficiente possível, na garantia de condições de vida digna aos cidadãos. Para tanto, destacam Benedicto de Vasconcellos Luna Gonçalves Patrão e Rosângela Maria de Azevedo Gomes:

Para alcançarmos o ideal de qualidade de vida imposto por nosso ordenamento jurídico, fundado no Princípio da Dignidade humana (art. $1^{\circ}$, inc. III, da CF/88), é de suma importância compreender a nova ordem jurídico-urbanística nacional, desenvolvida através da democratização do processo decisório, em que a descentralização das políticas públicas, com o fortalecimento dos Municípios, ganha relevante destaque. (GOMES; PATRÃO, 2014, p. 46).

No que diz respeito ao plano diretor, concebido como principal instrumento da política de desenvolvimento e expansão urbana, ressalta-se a essencialidade dele na gestão eficiente da cidade, compatibilizando crescimento econômico e desenvolvimento socioambiental, eis que direciona a atuação do Poder Público municipal em atenção às peculiaridades do município e região a qual está integrado, diante da atuação local do ente federativo.

O Plano Diretor caracteriza-se como o principal instrumento utilizado para garantia de desenvolvimento e sustentabilidade urbana, criando um sistema de planejamento e gestão da cidade no sentido de orientar as políticas públicas a serem desenvolvidas nos próximos anos em todas as áreas da administração pública municipal. (...) Portanto, o Plano Diretor é o melhor instrumento para garantir a qualidade de vida, mantendo de forma sustentável o equilíbrio da sociedade. (JESUS; FERREIRA, 2010, p. 01). 
O Estatuto da Cidade, ao estabelecer as diretrizes gerais da política urbana, assim dispõe em seu art. $2^{\circ}$ :

Art. $2^{\circ} \mathrm{A}$ política urbana tem por objetivo ordenar o pleno desenvolvimento das funções sociais da cidade e da propriedade urbana, mediante as seguintes diretrizes gerais:

I. garantia do direito a cidades sustentáveis, entendido como o direito à terra urbana, à moradia, ao saneamento ambiental, à infraestrutura urbana, ao transporte e aos serviços públicos, ao trabalho e ao lazer, para as presentes e futuras gerações (...). (BRASIL, 2001).

Em atenção à garantia do direito às cidades sustentáveis, o Estatuto da Cidade destacou a primordialidade de uma gestão eficiente do meio urbano, impondo, para tanto, o planejamento da atuação estatal, por meio do Plano Diretor, de modo a direcionar o crescimento das cidades, em atenção ao desenvolvimento sustentável. De fato, é com a edição da Lei 10.257, de 2001, que foram definidas as bases para a elaboração dos Planos Diretores, que passaram a ser denominados "planos diretores participativos" (PINTO, p. 103), enquanto parte integrante do processo de planejamento municipal, a teor da lição de Adilson Abreu Dallari e Sérgio Ferraz:

O plano diretor é o mais importante instrumento de planificação urbana previsto no direito brasileiro, sendo obrigatório para alguns Municípios e facultativo para outros; deve ser aprovado por lei e tem, entre outras prerrogativas, a condição de definir qual a função social a ser atendida pela propriedade urbana e de viabilizar a adoção dos demais instrumentos de implementação da política urbana. (DALLARI; FERRAZ, 2006, p. 324).

É através do plano diretor que serão elaboradas as bases para uma gestão eficiente da cidade, em atenção aos anseios sociais por uma cidade sustentável e integradora, que vai muito além da mera previsão de interesses privados, mas sim está em consonância com sua função social de resguardar e equilibrar os interesses de todos os cidadãos, a teor do disposto no art. 39, da Lei 10.257, de 2001:

Art. 39. A propriedade urbana cumpre sua função social quando atende às exigências fundamentais de ordenação da cidade expressas no plano diretor, assegurando o atendimento das necessidades dos cidadãos quanto à qualidade de vida, à justiça social e ao desenvolvimento das atividades econômicas, respeitadas as diretrizes previstas no art. $2^{\circ}$ desta Lei. (BRASIL, 2001).

A obrigatoriedade da elaboração do plano diretor está prevista no art. 41, do Estatuto da Cidade, impondo-se a previsão de certos conteúdos mínimos (art. 42), necessários ao efetivo atendimento das diretrizes estabelecidas pela Lei 10.257/2001, entre eles a delimitação das áreas urbanas, onde poderá ser aplicado o parcelamento, edificação ou utilização compulsória, considerando, ainda, a existência de infraestrutura essencial para o atendimento das diretrizes, 
bem como instrumentos específicos para proteção ambiental. Os planos diretores emergem, de fato, como mecanismo hábil a direcionar a atuação do gestor municipal, abarcando as diversas perspectivas da cidade, conforme leciona Victor Carvalho Pinto:

De um modo geral, os planos elaborados nesse contexto abordaram principalmente temas propriamente urbanísticos, como zoneamento, gestão do uso do solo, sistema viário, habitação e patrimônio histórico. Em menor medida, foram incorporados também os temas de saneamento ambiental, da mobilidade urbana e do meio ambiente. (PINTO, 2014, p. 103).

Ainda sobre a essencialidade do plano diretor na gestão sustentável das cidades, destaca SAYAGO e PINTO:

É por meio do plano que se define o melhor modo de ocupar um município ou região, prever as áreas onde se localizarão os pontos de lazer, as atividades industriais e todos os usos do solo, não somente no presente, mas também no futuro. Isso permitirá a consolidação de valores com vistas à qualidade de vida urbana. (SAYAGO; PINTO, 2005, p. 07).

Dito isso, o plano diretor deve ser concebido como uma ferramenta do poder público municipal na gestão eficiente e sustentável da cidade, sendo certo que esta gestão deve compreender a participação de todos os munícipes, enquanto atores sociais, nos termos asseverados por Edson Ricardo Saleme e Solange Teles da Silva:

O Estatuto da Cidade foi inovador ao instituir as diretrizes de política urbana prevendo a necessidade da ampla participação popular na formulação do plano diretor, como também a garantia à gestão democrática da cidade (...). Isso é o que se denomina planejamento participativo, o qual conta com a contribuição e fiscalização popular para ser definitivamente implementado. (SALEME; SILVA, 2007, p. 1509).

Destaca-se que o próprio Estatuto da Cidade, em seu art. 40, prevê os mecanismos indispensáveis na garantia dessa participação popular na elaboração e fiscalização do plano diretor, evidenciando a essencialidade da promoção de audiências públicas e debates, eis que o planejamento urbano incumbe não só ao poder público, mas também aos indivíduos, "haja vista que ambos são co-responsáveis pela sustentabilidade das cidades". (SAYAGO; PINTO, 2005, p. 12).

\section{A PARTICIPAÇÃO POPULAR NA GESTÃO DA CIDADE}

O planejamento das políticas urbanas, como uma das funções do Poder Público (FURQUIM, 2014), visa direcionar a atuação estatal no atendimento eficaz dos elementos indispensáveis à garantia de uma vida digna aos indivíduos, motivo pelo qual a participação popular na tomada de decisões políticas apresenta-se elementar na observância precisa dos anseios sociais. $O$ art. $1^{\circ}$, da Constituição Federal, estabelece que a República Federativa do Brasil tem, como fundamentos, entre outros, a soberania e a cidadania, preceituando, no parágrafo único, que todo o poder da 
República emana do povo, que o exerce de forma indireta ou direta, nos termos do texto constitucional.

A participação popular no planejamento das políticas públicas consagra a observância do cumprimento das funções do Estado em consonância com os interesses de todos os indivíduos, hábil a construir uma sociedade integradora, atenta a todas as peculiaridades de dada localidade, em atenção, ainda, às temporalidades a que está sujeita.

A cidade, enquanto "espaço urbano de convivência social, materializador das atividades humanas" (FIORILLO, 2013, p. 79), demanda, cada vez de forma mais latente, mecanismos capazes de promover uma reconstrução da sociedade, onde os indivíduos se reconheçam enquanto atores sociais, responsáveis pela construção de uma sociedade sustentável, com fins de justiça social, imbuindo em cada cidadão um verdadeiro sentimento de pertença.

É nesse sentido que o fortalecimento da participação popular na gestão da cidade, aliado, por óbvio, à garantia efetiva de direitos fundamentais expressamente previstos na Constituição Federal, a exemplo do direito a uma educação de qualidade e à informação, induz à reconstrução de uma sociedade mais justa, eis que os indivíduos se direcionam à persecução do bem-estar de todos, erigindo, assim, a cidade ideal almejada pelos cidadãos. (CARVALHO; KLEINRATH, 2014).

Fundamentando a essencialidade da participação popular no planejamento das políticas urbanas direcionadas à gestão eficiente da cidade, Jürgen Habermas oferece, através de sua Teoria do Agir Comunicativo, as bases para construção de uma sociedade integradora, através do diálogo intersubjetivo entre os atores sociais.

Para Habermas, é através da ação comunicativa que os indivíduos abertos ao diálogo são capazes de atingir um consenso onde todas as perspectivas e anseios são levados em consideração, destacando, para tanto, que:

os direitos só se tornam socialmente eficazes, quando os atingidos são suficientemente informados e capazes de atualizar, em casos específicos, a proteção do direito garantida através de direitos fundamentais de justiça. (...) A colaboração no processo de realização do direito cria um laço entre o status positivo de direito, valorizado em termos coletivos, e o status de cidadão ativo. (HABERMAS, 2012, p. 149).

É através do seu reconhecimento enquanto ator social que o cidadão é capaz de contribuir para que o desenvolvimento do meio urbano possa alcançar níveis adequados de inclusão social e preservação do meio ambiente, em um verdadeiro espaço de convivência digna dos indivíduos. Para tanto, Habermas assevera que a legitimidade das normas jurídicas decorre da "autonomia pública dos cidadãos, os quais têm que decidir (em última instância) e enquanto atores de ordem 
jurídica, iguais em direitos, sobre os critérios da igualdade de tratamento". (HABERMAS, 2012, p. 154).

É, portanto, através da razão comunicativa que a ação dos indivíduos direciona-se na busca pela plena realização dos anseios sociais dos cidadãos, eis que implica no reconhecimento do outro e do mundo em que se vive. Nesse contexto, a teoria do agir comunicativo revela-se fundamental na análise das funções do Estado democrático de direito, no tocante à efetivação dos direitos fundamentais, eis que construído através do diálogo contínuo dos indivíduos, que se reconhecem mutuamente enquanto sujeitos de direitos e agentes sociais, essenciais na reconstrução de uma cidade integradora.

Nos termos asseverados por Mariana Mencio, o Estado brasileiro funda-se na participação popular por ser o povo "o titular e o ente escolhido para o exercício do poder político do Estado". (MENCIO, 2007, p. 39).

Por óbvio, não está a se afastar a participação indireta, denominada representativa, expressamente prevista no texto constitucional. No entanto, a participação popular direta, notadamente no que diz respeito à gestão do espaço urbano, mostra-se também imprescindível no direcionamento da atuação do Poder Público em atenção às pretensões sociais dos cidadãos, principalmente no que tange a crescente desvinculação, na atualidade, da atuação estatal frente aos interesses sociais fundamentais.

A participação popular no planejamento das políticas públicas reafirma a importância da gestão compartilhada do espaço urbano entre Poder Público e sociedade civil, de modo a aperfeiçoar a democracia participativa, "resultando que efetivamente a vontade popular prevaleça, fornecendo sentido de legitimidade às decisões políticas". (MENCIO, 2007, p. 61).

De fato, embora o ato de planejar seja "um ato de escolhas políticas e ideológicas", ele deve estar invariavelmente vinculado aos interesses sociais daquela localidade, devendo corresponder, portanto, às necessidades dos munícipes, notadamente no que diz respeito aos direitos indispensáveis a uma existência com dignidade, como o direito à moradia, ao lazer, entre outros. (ALOCHIO, 2010, p. 95).

Portanto, resta claro que o desenvolvimento urbano, em desatenção a uma política efetiva de planejamento, acarreta não só impactos ambientais de ordem natural, mas também a desigualdade social, nos termos destacados por Helano Márcio Vieira Rangel e Jacilene Vieira da Silva:

As desigualdades sociais produzem a exclusão social e a marginalização de grupos sociais com baixo poder aquisitivo, fato que os distanciam cada vez 
mais de uma moradia digna e do direito a uma cidade autossustentável. (...) As desigualdades se tornaram tão patentes, que se estabeleceu uma segregação urbana, com a formação de duas cidades: 'a legal' e a 'informal'. (RANGEL e SILVA, 2009, p. 70).

Nesse sentido, evidencia-se a importância da manifestação dos cidadãos quando da elaboração ou até mesmo fiscalização de políticas públicas que digam respeito ao desenvolvimento da cidade, em uma verdadeira construção de um espaço de convivência integrador e condizente com a realidade social.

O Estado democrático de direito pressupõe a participação popular na elaboração e fiscalização das decisões políticas tomadas pelo Poder Público, eis que a legitimidade da sua atuação decorrer do próprio povo, sendo certo que esta participação dos indivíduos "permite que a sociedade seja parte atuante nas decisões políticas ambientais", com a possibilidade de se chegar "a um entendimento comum, que vai orientar as políticas públicas". (GONÇALVES; CASTRO, 2014).

A participação popular deve corresponder, assim, a uma atuação efetiva e consciente da população, que deve se apresentar bem informada e crítica em relação às informações e aos elementos que Ihes serão passados, atentos, portanto, às expectativas socioambientais de toda a população. Corroborando tal afirmativa, o Estatuto da Cidade, que regulamenta os arts. 182 e 183, da Constituição Federal, e estabelece as diretrizes gerais da política urbana dispõe, em seu art. $2^{\circ}$ :

Art. $2^{\circ}$ A política urbana tem por objetivo ordenar o pleno desenvolvimento das funções sociais da cidade e da propriedade urbana, mediante as seguintes diretrizes gerais:

(...)

II. gestão democrática por meio da participação da população e de associações representativas dos vários segmentos da comunidade na formulação, execução e acompanhamento de planos, programas e projetos de desenvolvimento urbano (...). (BRASIL, 2001).

Objetivando assegurar a efetiva participação popular na gestão do meio ambiente urbano, o próprio Estatuto da Cidade prevê, em seu art. 43, alguns instrumentos a serem utilizados na garantia dessa gestão democrática, garantindo o controle direto das atividades estatais "e o pleno exercício da cidadania". (BRASIL, 2001).

Entre os instrumentos previstos no Estatuto, destaca-se a previsão de audiências públicas, que instrumentalizam essa participação popular na gestão da cidade, de modo a "aperfeiçoar a legitimidade das decisões estatais". (BIM, 2014, p. 35).

Impõe-se asseverar, dessa forma, que a essa participação popular devem ser disponibilizados instrumentos eficientes que sejam capazes de efetivar a participação dos indivíduos na tomada de decisões políticas, por parte da Administração Pública, evitando que as 
manifestações não se resumam a um mero cumprimento de requisitos, conforme destaca Vinícius Lott Thibau:

Na perspectiva do paradigma jurídico-constitucional do Estado democrático de direito, de nada adianta a simples oferta legislativa de inúmeras técnicas destinadas ao exercício dos direitos de participação e de fiscalização na tomada de decisões pelos destinatários dos seus efeitos, se essas decisões não advierem de discursos que se desenvolvam livres de coerção e, também, não vincularem inequivocamente $\mathrm{E}$ Estado, no âmbito das funções legislativa, executiva e judiciária. (THIBAU, 2012, p. 29).

Impõe-se, portanto, a efetiva observância dos instrumentos legais destinados ao exercício da participação popular na gestão do espaço urbano, demonstrando-se essencial o fortalecimento deles na construção de uma cidade justa e igualitária.

Nesse cenário, as audiências públicas urbanísticas emergem como mecanismos fundamentais na gestão eficiente e compartilhada do meio ambiente urbano, eis que implicam na participação dos indivíduos que se mostram interessados no desenvolvimento sustentável da cidade, orientando as políticas públicas de modo a corresponderem às necessidades socioambientais de dada localidade.

\section{As audiências públicas no plano diretor}

Com o intuito de aproximar os indivíduos das deliberações realizadas pelos gestores municipais, notadamente no que diz respeito ao planejamento das políticas urbanas, a Lei 10.257, de 2001, prevê, entre outros instrumentos de concretização da participação social, as audiências públicas, que têm como objetivo "conferir maior legitimidade ao plano diretor, assegurando o cumprimento dos princípios da gestão democrática da cidade e da participação popular". (ZANDONADE; ROSSI, ano, p. 21).

A participação popular direta implica, de fato, na construção de uma sociedade integradora, de modo que os indivíduos se reconheçam enquanto atores sociais (HABERMAS, 2012), manifestando-se a respeito dos caminhos a serem percorridos pela sociedade. A esse respeito, destaca Márcio Renan Hamel:

Uma vez que a vontade legítima emana de cidadãos politicamente autônomos, os quais são parceiros do direito e da democracia, o processo legislativo passa a ser espaço de integração social. É o espaço onde mulheres, negros, trabalhadores e minorias raciais irão expor as demandas sociais necessárias, transformando também o direito em fonte de integração social, através de um arranjo comunicativo. (HAMEL, 2009, p. 136).

As audiências públicas, expressamente previstas no art. 43, do Estatuto da Cidade, garantem a gestão democrática da cidade, direcionando a atuação da Administração Pública, por 
meio da participação popular, na estrita observância dos anseios sociais. Eduardo Fortunato Bim destaca que as audiências públicas, enquanto instrumentos de participação, "aproximam o cidadão dos assuntos da polis/civitase da responsabilidade na gestão da res publicae, ou seja, eles educam o cidadão para a democracia". (2014, p. 35).

Evidencia-se, dessa forma, a essencialidade da gestão participativa da cidade, eis que implica na consideração dos interesses sociais, garantindo aos indivíduos uma maior ingerência sobre as decisões políticas a serem tomadas pelo Poder Público e que irão impactar diretamente na vida de cada um deles, nos termos defendidos por Eduardo Fortunato Bim:

Na irretocável doutrina de Antônio Cabral, a audiência pública simplesmente tem a função de colher impressões e demandas da comunidade envolvida sobre tema que será objeto de decisão administrativa. Geralmente, ela serve para instruir o processo administrativo visando subsidiar a decisão administrativa para um resultado mais afinado com as necessidades sociais. (BIM, 2014, p. 71).

A audiência pública urbanística apresenta-se como instrumento hábil a garantir que a atuação estatal oriente-se, da melhor forma possível, no atendimento dos anseios sociais, direcionando a elaboração e a implantação de políticas públicas condizentes com a realidade urbana, conforme destaca Mariana Mencio, de modo a mitigar a segregação social de alguns grupos da sociedade civil:

De um lado, a audiência pública permite que o administrado manifeste sua opinião com vistas à melhor decisão do Poder Público. De outro, a audiência pública consiste no debate público, ocasião em que o administrado pode confrontar seus pontos de vista, tendências, opiniões, razões e opções com os de outros administrados e com os do próprio Poder Público, com o intuito de contribuir para a melhor decisão administrativa. (MENCIO, 2007, p. 112).

A atuação do poder público, através da gestão do espaço urbano, deve, de fato, ser capaz de garantir aos indivíduos os direitos fundamentais expressamente preconizados pela Constituição Federal, notadamente no que diz respeito ao direito à moradia, à educação, à segurança, ao lazer, à saúde, ao trabalho, entre outros.

Nesse sentido, a gestão compartilhada do meio ambiente urbano implica na elaboração de políticas públicas condizentes com a realidade e os anseios sociais, assegurando aos indivíduos a possibilidade de participar da construção de uma cidade sustentável, conforme leciona Mariana Mencio:

É possível concluir que a gestão democrática das cidades deve ser considerada uma decisão coletiva, compartilhada entre a administração pública e a sociedade, resultando em um pacto social, em que os vários interesses envolvidos sejam ponderados de maneira a ordenar o território de 
forma sustentável, assegurando basicamente à população espaços adequados ao lazer, transporte, habitação e trabalho. (MENCIO, 2007, p. 98).

Em atenção à essencialidade da participação popular na gestão das cidades, a Lei 10.257, de 2001, ao dispor sobre o plano diretor, principal instrumento da política de desenvolvimento e expansão urbana, estabeleceu, em seu art. $40, \S 4^{\circ}$, a promoção de audiências públicas, hábeis a garantir que os interesses sociais fossem, de fato, levados em consideração, quando da elaboração de políticas urbanas:

Art. 40. O plano diretor, aprovado por lei municipal, é o instrumento básico da política de desenvolvimento e expansão urbana.

(...)

$\S 4$ - No processo de elaboração do plano diretor e na fiscalização de sua implementação, os Poderes Legislativo e Executivo municipais garantirão:

I. a promoção de audiências públicas e debates com a participação da população e de associações representativas dos vários segmentos da comunidade (...). (BRASIL, 2001).

Evidencia-se, dessa forma, que a participação popular se apresenta, no Estatuto da Cidade, "como um mecanismo de contenção da discricionariedade administrativa do administrador ao elaborar o projeto de Lei", em um verdadeiro exercício, por parte dos indivíduos, da cidadania expressa no art. $1^{\circ}, 11$, da Constituição Federal. (MENCIO, 2007, p. 96).

Mariana Mencio assevera que a gestão compartilhada do meio urbano, notadamente no que diz respeito à elaboração e aprovação do Plano Diretor, "demonstra que o processo é coletivo e não obra ou trabalho exclusivo dos órgãos técnicos ou da consultoria contratada para auxiliar nesse processo", trazendo para a própria população a discussão a respeito do que deve ser feito pela cidade em termos de desenvolvimento socioeconômico sustentável. (2007, p. 95).

Destaca-se que a participação popular na elaboração e fiscalização do plano diretor resulta importante mecanismo de orientação e fiscalização da atuação estatal, implicando, assim, no planejamento das políticas públicas de forma mais eficiente e condizente com a realidade social.

O intuito da gestão democrática da cidade, regulado pelo Estatuto da Cidade, é procurar fazer com que os instrumentos da política urbana, disciplinados no art. $4^{\circ}$, da Lei Federal, não sejam meras ferramentas a serviço de concepções tecnocráticas, mas, ao contrário, verdadeiros instrumentos de promoção do direito à cidade para todos, sem exclusão, procurando garantir o pleno desenvolvimento das funções sociais da cidade e o bem-estar de seus habitantes, nos termos do art. 182, da Constituição Federal. (MENCIO, 2007, p. 106).

De fato, a previsão, na lei federal, da necessária realização de audiência pública quando da elaboração e fiscalização do plano diretor, corrobora a importância da participação popular no 
planejamento municipal, de modo a possibilitar aos moradores a oportunidade de serem ouvidos, enquanto partes integrantes do processo de construção de uma cidade sustentável.

A audiência pública, conforme previsto no Estatuto da Cidade, não vincula os órgãos públicos no tocante à manifestação dos indivíduos. Contudo, ela deve ser utilizada para orientar a atuação do gestor público municipal no planejamento das políticas urbanas, de modo a implantar políticas públicas condizentes com a realidade social. Tal perspectiva afasta a Administração Pública, quando da elaboração do plano diretor, dos denominados planos prontos (ALOCHIO, 2010), que acabam sendo elaborados de forma completamente desvinculada da realidade urbana local, nos termos expressos por Sarah Lúcia Alves França:

A democratização do plano diretor é fundamental para romper esse vício de projetos e planos prontos em escritórios e compartilhar o processo com todos os cidadãos, assumido por todos os atores. A participação popular nas decisões urbanas não é só um convite, e sim, um dever de todos os cidadãos. Dessa forma, o planejamento deixa de ser uma solução apenas técnica e passa a ser transformado em resultado de articulação política entre os diversos atores sociais que pactuam a vida da cidade. (FRANÇA, p. 36).

Nota-se que a realização de audiência pública, quando da elaboração e fiscalização do plano diretor, permite uma maior integração da sociedade, sendo certo que os indivíduos, ao participarem do processo de planejamento e desenvolvimento da cidade, se reconhecem mutuamente, através das políticas públicas que serão implantadas, como sujeitos de direitos e atores sociais, na construção de uma sociedade justa e igualitária.

Em atenção à importância da participação popular no planejamento das políticas urbanas municipais, evidencia-se que tal participação deve mostrar-se efetiva quando da elaboração e fiscalização do plano diretor, restando inconcebível que as audiências públicas se limitem a mero requisito procedimental, sem a concreta observância das manifestações sociais no tocante à orientação da atuação do Poder Público.

Para tanto, Mariana Mencio sustenta que a participação popular se apresenta eficiente "no momento em que os órgãos públicos, que estiverem conduzindo o processo, realizarem todos os esforços para atingirem a melhor decisão administrativa ou legal, contemplando todos os pontos de vista expostos pelos administrados. (MENCIO, 2007 p. 136).

Assim, impõe-se que a Administração Pública municipal tenha especial atenção em relação à realização das audiências públicas, de modo que elas se mostrem eficazes na orientação da atuação estatal, correspondendo à efetiva manifestação da população quando da apresentação das propostas e outras manifestações do ente municipal, conforme destaca Adriana Zandonade e Roberta Lessa Rossi: 
De toda sorte, os argumentos apresentados pelos interessados em audiência pública, acolhidos ou não, devem ser objeto de consideração explícita, por parte do Poder Público, compondo a motivação da decisão adotada. Desse modo, constituem importante instrumento a serviço do controle da própria constitucionalidade da lei do plano diretor que vier a ser aprovada. (ZANDONADE; ROSSI, 2007, p. 23).

Destaca-se que o Estatuto da Cidade não prevê qualquer procedimento a ser observado quando da realização das audiências públicas, limitando-se a prescrever, em seu art. 40, parágrafo $4^{\circ}$, a necessidade de realização delas quando da elaboração do plano diretor e na fiscalização de sua implementação.

Nesse contexto, a ausência de previsão de um procedimento a ser adotado para a realização das audiências públicas urbanísticas acaba enfraquecendo o instituto da participação popular no planejamento e gestão das cidades, de forma que a discricionariedade da Administração Pública acaba prevalecendo em detrimento da manifestação dos indivíduos.

Com o intuito de compatibilizar o processo de desenvolvimento e expansão urbana, instrumentalizado através do Plano Diretor, com os preceitos de gestão democrática da Cidade, preconizada pela Lei 10.257, de 2001, o Ministério das Cidades, através da Resolução 25, de 2005, dispôs sobre o procedimento a ser adotado para concretizar a participação da população nos processos de elaboração e fiscalização da implantação do Plano Diretor, dispondo, para tanto, em seu art. $3^{\circ}$ e $4^{\circ}$ :

Art. 3o O processo de elaboração, implementação e execução do Plano diretor deve ser participativo, nos termos do art. 40, § 4 o e do art. 43 do Estatuto da Cidade.

§1ㅇ A coordenação do processo participativo de elaboração do Plano Diretor deve ser compartilhada, por meio da efetiva participação de poder público e da sociedade civil, em todas as etapas do processo, desde a elaboração até a definição dos mecanismos para a tomada de decisões.

$\S 2$ ㅇ Nas cidades onde houver Conselho das Cidades ou similar que atenda os requisitos da Resolução № 13 do CONCIDADES, a coordenação de que trata o $§ 1$, , poderá ser assumida por esse colegiado.

Art. 4 № processo participativo de elaboração do plano diretor, a publicidade, determinada pelo inciso II, do $\S 4$ o do art. 40 do Estatuto da Cidade, deverá conter os seguintes requisitos:

I. Ampla comunicação pública, em linguagem acessível, através dos meios de comunicação social de massa disponíveis;

II. Ciência do cronograma e dos locais das reuniões, da apresentação dos estudos e propostas sobre o plano diretor com antecedência de no mínimo 15 dias;

III. Publicação e divulgação dos resultados dos debates e das propostas adotadas nas diversas etapas do processo. (BRASIL, 2005).

A Resolução supramencionada foi editada pelo Conselho das Cidades, órgão integrante do Ministério das Cidades, que tem por atribuição a proposição de diretrizes gerais para a 
formulação e implementação da Política Nacional de Desenvolvimento Urbano, em atenção ao disposto no Decreto $n^{\circ} 5.790$, de 2006, que dispõe sobre composição, estruturação, competências e funcionamento do órgão. (BRASIL, 2006).

Destaca-se que embora tenha apenas um caráter de recomendação (BIM, 2014), a Resolução do Conselho da Cidade mostra-se como um importante instrumento legal no aperfeiçoamento das audiências públicas urbanísticas, eis que estabelece elementos indispensáveis na garantia de uma efetiva participação social no planejamento e na gestão das cidades.

No tocante à definição de um procedimento a ser adotado para a realização das audiências públicas, afigura-se primordial a exposição de diretrizes capazes de assegurar a participação efetiva dos indivíduos no processo de planejamento das políticas urbanas, orientando os gestores municipais "a conduzirem este processo de elaboração dos Planos Diretores de modo a respeitarem os preceitos democráticos do Estado Brasileiro". (MENCIO, 2007, p. 142).

Denota-se que a Resolução 25, de 2005, pretende, a exemplo do disposto em seu art. $8^{\circ}$, elucidar os elementos indispensáveis na elaboração de políticas urbanas, que sejam capazes de integrar Poder Público e sociedade civil.

Art. 8ㅇ As audiências públicas determinadas pelo art. 40, § 4으, inciso I, do Estatuto da Cidade, no processo de elaboração de plano diretor, têm por finalidade informar, colher subsídios, debater, rever e analisar o conteúdo do Plano Diretor Participativo, e deve atender aos seguintes requisitos:

I. Ser convocada por edital, anunciada pela imprensa local ou, na sua falta, utilizar os meios de comunicação de massa ao alcance da população local;

II. Ocorrer em locais e horários acessíveis à maioria da população;

III. Serem dirigidas pelo Poder Público Municipal, que após a exposição de todo o conteúdo, abrirá as discussões aos presentes;

IV. Garantir a presença de todos os cidadãos e cidadãs, independente de comprovação de residência ou qualquer outra condição, que assinarão lista de presença;

V. Serem gravadas e, ao final de cada uma, lavrada a respectiva ata, cujos conteúdos deverão ser apensados ao Projeto de Lei, compondo memorial do processo, inclusive na sua tramitação legislativa. (BRASIL, 2005).

A participação popular no planejamento das cidades manifesta-se, portanto, como componente substancial da gestão do meio ambiente urbano, trazendo os cidadãos para o centro das deliberações políticas, resultando na inerente reconstrução da sociedade de forma integradora e justa. Por óbvio, a participação da sociedade civil nas deliberações realizadas pelo Poder Público municipal, notadamente no que diz respeito às audiências públicas urbanísticas, deve ser 
viabilizada de forma adequada, consciente e eficaz, de modo a aperfeiçoar o papel dos indivíduos enquanto atores sociais, fortalecendo a gestão compartilhada das cidades.

\section{CONCLUSÃO}

A cidade, enquanto meio onde os indivíduos exercitam suas capacidades, não pode mais ser concebida como local de exclusão social e degradação do meio ambiente, impondo-se, para tanto, uma alteração de postura, por parte do Poder Público e da sociedade civil, que implique na reconsideração do outro e no respeito ao meio ambiente.

De fato, o processo de urbanização ocorrido no Brasil, desvinculado de um planejamento efetivo da atuação estatal, acarretou um crescimento desordenado das cidades, implicando em um desenvolvimento excludente e gerador de impactos ambientais, transformando a cidade em um verdadeiro meio de degradação socioambiental.

É nesse cenário que o planejamento da atuação estatal se mostra primordial no desenvolvimento sustentável das cidades, impondo uma visão global do meio em que se vive, de modo a compatibilizar o desenvolvimento socioeconômico com a garantia de direitos fundamentais, entre eles o direito ao meio ambiente ecologicamente equilibrado, preconizado no art. 225, da Constituição Federal.

Na construção de uma sociedade integradora, demanda-se um efetivo planejamento da atuação da Administração Pública, que deve mostrar-se completamente vinculada aos anseios sociais, motivo pelo qual a gestão compartilhada das cidades mostra-se inerente ao denominado desenvolvimento sustentável do meio ambiente urbano, eis que implica no direcionamento da atuação estatal aos anseios da sociedade como um todo.

A participação popular na gestão do meio ambiente urbano, instrumentalizada pela audiência pública prevista quando da elaboração do plano diretor, possui fundamental importância na orientação da atuação estatal, direcionando-a precipuamente no atendimento eficaz dos anseios sociais, através de políticas públicas condizentes com a realidade local.

O fortalecimento dos instrumentos democráticos de planejamento e gestão urbana viabiliza a participação da sociedade civil na elaboração de políticas urbanas, direcionando a atuação do Poder Público no atendimento concreto e eficaz do anseio social por uma vida com qualidade. 


\section{REFERÊNCIAS}

ALOCHIO, Luiz Henrique Antunes. Plano Diretor Urbano e Estatuto da Cidade: medidas cautelares e moratórias urbanísticas. Belo Horizonte: Fórum, 2010.

BIM, EDUARDO FORTUNATO. Audiências Públicas. São Paulo: Revista dos Tribunais, 2014.

BRASIL. Constituição Federal de 1988. Vade Mecum. São Paulo: Saraiva, 2013.

Decreto no 5.790 , de 25 de maio de 2006. Dispõe sobre a composição, estruturação, copetência e funcionamento do Conselho das Cidades - ConCidades e dá outras providências. Disponível em: http://www.planalto.gov.br/ccivil_03/_ato2004-2006/2006/Decreto/D5790.htm. Acesso em: 15 out. 2015.

Lei 10.257 , de 10 de julho de 2001. Estatuto da Cidade. Regulamenta os arts. 182 e 183 da Constituição Federal, estabelece diretrizes gerais da política urbana e dá outras providencias. Vade Mecum. São Paulo: Saraiva, 2013.

Resolução no 25, de 18 de março de 2005. Dispõe sobre o processo participativo na elaboração de planos diretores. Disponível em: http://multimidia.curitiba.pr.gov.br/2014/00146672.pdf. Acesso 08 out. 2015.

CARVALHO, Newton Teixeira; KLEINRATH, Stella de Moura. Sustentabilidade Ambiental. In: RIOS, Mariza. et al. (Coord.). A cidade real e a cidade ideal: em uma reflexão transdisciplinar. Belo Horizonte: Del Rey, 2014.

CYMBALISTA, Renato. Refundar o não fundado: desafios da gestão democrática das políticas urbana e habitacional do Brasil. Instituto Pólis, 2005. Disponível em: http://www.polis.org.br/uploads/746/746.pdf. Acesso em 28/09/2015. Acesso em: 19 out. 2015.

COSTA. Beatriz Souza; Rios, Mariza. A cidade: o contexto urbano e os impactos ambientais. In: RIOS, Mariza. et al. (Coord.). A cidade real e a cidade ideal: em uma reflexão transdisciplinar. Belo Horizonte: Del Rey, 2013.

DALLARI, Adilson Abreu; FERRAZ, Sérgio. Estatuto da cidade: comentários à lei federal 10.257/2001. 2a Ed. São Paulo: Malheiros, 2006.

FERNANDES, Edésio. A nova ordem jurídico-urbanística no Brasil. In: ALFONSIN, Betânia; FERNANDES, Edésio (org.). Direito urbanístico: estudos brasileiros e internacionais. Belo Horizonte: Del Rey, 2006.

FIORILLO, Celso Antonio Pacheco. Curso de Direito Ambiental Brasileiro. 14. ed. São Paulo: Saraiva, 2013.

FRANÇA, Sarah Lúcia Alves. Grupo de Trabalho: participação e poder público. A participação popular nos Planos Diretores municipais: uma estratégia de gestão democrática. Disponível em: http://gestaocompartilhada.pbh.gov.br/sites/gestaocompartilhada.pbh.gov.br/files/biblioteca/arqu ivos/planos_diretores_e_participacao_popular_0.pdf. Acesso em: 19 out. 2015. 
FURQUIM, Cláudia do Amaral. Aspectos jurídicos do planejamento urbano no Brasil. In: RIOS, Mariza. et al. (Coord.). A cidade real e a cidade ideal: em uma reflexão transdisciplinar. Belo Horizonte: Del Rey, 2014.

GONÇALVES, Daniela Oliveira; CASTRO, Clarice Rogério de. O Princípio da participação nas questões ambientais e a teoria do agir comunicativo de Habermas. In: REIS, Émilien Vilas Boas (org). Entre a filosofia e o ambiente: bases filosóficas para o direito ambiental. Belo Horizonte: 3i Editora, 2014.

HABERMAS, Jürgen. Direito e Democracia: entre factividade e validade. Vol. I. Trad. Flávio Beno Siebeneichler. Rio de Janeiro: Tempo Brasileiro, 2011.

HAMEL, Márcio Renan. O Estatuto das Cidades e o princípio da participação popular: uma análise da política deliberativa de Habermas para o desenvolvimento. Revista Urutágua. N 18. Maringá, 2009. Disponível em: http://ojs.uem.br/ojs/index.php/Urutagua/article/viewFile/4989/4049. Acesso em 22 out. 2015.

JESUS, lago Santana de; FERREIRA, Gabriel Luis BonoraVidrih. Participação da sociedade civil no Plano Diretor. Revista Anais do Sciencult. V. 1, $n^{\circ}$ 3. 2010. Disponível em: http://periodicos.uems.br/novo/index.php/anaispba/article/viewFile/256/188. Acesso e 08 out. 2015.

LEFF, Enrique. Complexidade, Interdisciplinaridade e Saber Ambiental. In PHILIPPI JR, Arlindo et al. Interdisciplinaridade em Ciências Ambientais. São Paulo: Signus, 2000. p. 19-51. Disponível em: https://scholar.google.com.br/scholar?q=Complexidade,+interdisciplinaridade+e+saber+ambiental \&hl=ptBR\&as_sdt=0\&as_vis=1\&oi=scholart\&sa=X\&ei=qgQ9VeOPHoSigwToo4CABw\&ved=0CBoQg QMwAA\#. Acesso em: 08 out. 2015.

LEONARDO, Elizandra Litaiff. O direito urbanístico como disciplina indispensável para a implementação das cidades sustentáveis. Trabalho publicado nos Anais do XIX Encontro Nacional do Conpedi. $\quad 2010 . \quad$ Dortaleza, em: file:///C:/Users/d04849/Downloads/eb7c33677127bd80e893d4575e86bc56\%20(1).pdf. Acesso em 08 out. 2015.

MACHADO, Paulo Affonso Leme. Direito Ambiental Brasileiro. $15^{\circ}$ ed. atual. ampl. São Paulo: Malheiros, 2007.

MARQUES, José Roberto. Meio Ambiente Urbano. 2. ed. Rio de Janeiro: Forense, 2010.

MENCIO, Mariana. As consequências jurídicas advindas da falta de participação popular durante o processo de elaboração e aprovação do plano diretor. Revista MPMG Jurídico. Ano I, n. 4. Belo Horizonte, $2006 . \quad$ Disponível em: https://aplicacao.mpmg.mp.br/xmlui/bitstream/handle/123456789/839/3.2.2\%20As\%20conseque ncias\%20jur\%C3\%ADdicas.pdf?sequence=1. Acesso em: 23 out. 2015.

Regime jurídico da audiência pública na gestão democrática das cidades. Belo Horizonte: Fórum, 2007.

MILARÉ, Édis. Direito do Ambiente: a gestão em foco: doutrina, jurisprudência, glossário. 7. ed. São Paulo: Revista dos Tribunais, 2011. 
MURAD, Samir Jorge. O Estatuto da Cidade e a proteção ambiental. In: BRAGA FILHO, Edson de Oliveira et al. (Coord.) Mecanismos Legais para o desenvolvimento sustentável. Belo Horizonte: Fórum, 2010.

PATRÃO, Benedicto de Vasconcellos Luna Gonçalves; GOMES, Rosângela Maria de Azevedo. O direito à cidade sob a perspectiva do direito de família: o direito à convivência comunitária e a proteção jurídica da criança e do adolescente no contexto urbano. IN: AIETA, Vania. (coord). Cadernos de direito da cidade: estudos em homenagem à professora Maria Garcia: série I. Rio de Janeiro: Lumem Juris, 2014.

PINTO, Victor Carvalho. Direito Urbanístico: plano diretor e direito de propriedade. $4^{\circ}$. ed. rev. e atual. e ampl. São Paulo: Revista dos Tribunais, 2014.

PLATÃO. A República. Trad. Enrico Corvisieri. São Paulo: Nova Cultural, 2000.

RANGEL, Helano Márcio Vieira; SILVA, Jacilene Vieira da. O direito fundamental à moradia como mínimo existencial e a sua efetivação à luz do estatuto da cidade. Revista Veredas do Direito: Direito Ambiental e Desenvolvimento Sustentável. V. 6, n. 12. Belo Horizonte, 2009.

SALEME, Edson Ricardo; SILVA, Solange Teles da. Plano Diretor, Participação Popular e Responsabilidades. In: XVI CONGRESSO NACIONAL DO CONPEDI. Belo Horizonte, 2007. Disponível em:

http://www.publicadireito.com.br/conpedi/manaus/arquivos/anais/bh/edson_ricardo_saleme.pdf. Acesso em 15 out. 2015.

SAYAGO, Doris; PINTO, Mariana Oliveira. Plano Diretor: instrumento de política urbana e gestãoambiental. VI Encontro Nacional da ECOECO - Brasília (DF) - 2005. Disponível em: http://www.ecoeco.org.br/conteudo/publicacoes/encontros/vi_en/artigos/mesa3/des_urbano_me ioambiente.pdf. Acesso em: 08 out. 2015.

SILVA, José Afonso da. Direito Urbanístico Brasileiro. São Paulo: Malheiros, 2010.

THIBAU, Vinícius Lott. Estado democrático de direito e gestão urbana compartilhada. IN: RIOS, Mariza; CARVALHO, Newton Teixeira (coord). Direito à cidade: moradia e equilíbrio ambiental. Belo Horizonte: Del Rey, 2012.

ZANDONADE, Adriana; ROSSI, Roberta Lessa. A audiência pública nos processos de elaboração e revisão do plano diretor. Revista Depoimentos. $n^{\circ}$ 11. Vitória, 2007. Disponível em: http://www.fdv.br/publicacoes/periodicos/revistadepoimentos/n11/4.pdf. Acesso em 19 out. 2015.

Trabalho enviado em 01 de junho de 2016.

Aceito em 19 de julho de 2016. 